\title{
Retraction Note to: Genome sequence and genome mining of a marine-derived antifungal bacterium Streptomyces sp. M10
}

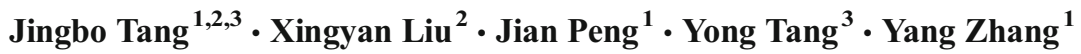

Published online: 8 October 2015

(C) Springer-Verlag Berlin Heidelberg 2015

Retraction Note to: Appl Microbiol Biotechnol (2015)

$$
\text { 99:2763-2772 }
$$

DOI 10.1007/s00253-015-6453-0

The Editor-in-Chief and the Associate Editors have decided to retract this article.

Upon investigation carried out according to the Committee on Publication Ethics guidelines, it has been found that the authors submitted an unpublished paper of which they are not the original authors.

The authors admitted their misconduct and agreed to retract this article.

The online version of the original article can be found at http://dx.doi.org/ 10.1007/s00253-015-6453-0.

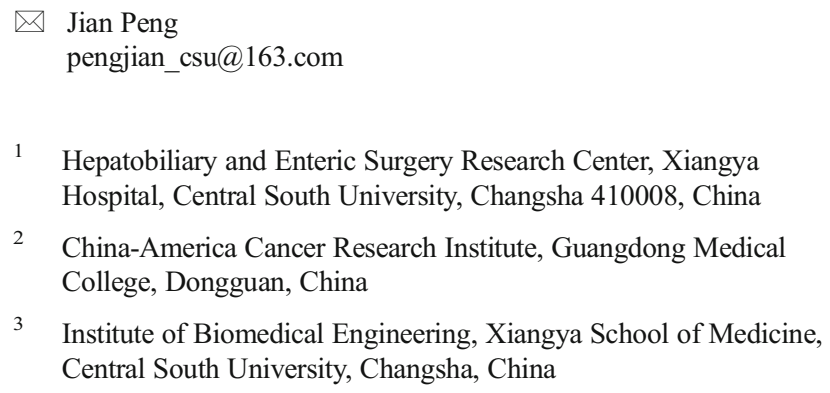

3 Institute of Biomedical Engineering, Xiangya School of Medicine, Central South University, Changsha, China 